Atmos. Chem. Phys., 3, 581-589, 2003

www.atmos-chem-phys.org/acp/3/581/

Atmospheric Chemistry and Physics

\title{
On the formation of radiation fogs under heavily polluted conditions
}

\author{
H. Kokkola, S. Romakkaniemi, and A. Laaksonen \\ Department of Applied Physics, University of Kuopio, Finland \\ Received: 1 November 2002 - Published in Atmos. Chem. Phys. Discuss.: 3 February 2003 \\ Revised: 27 May 2003 - Accepted: 28 May 2003 - Published: 2 June 2003
}

\begin{abstract}
We have studied the effect of gaseous pollutants on fog droplet growth in heavily polluted air using a model that describes time-dependent sulfate production in the liquid phase and thermodynamical equilibrium between the droplets and the gas phase. Our research indicates that the oxidation of $\mathrm{SO}_{2}$ to sulfate has a significant effect on fog droplet growth especially when hygroscopic trace gases, for example $\mathrm{HNO}_{3}$ and $\mathrm{NH}_{3}$ are present. The increased sulfate production by dissolution of hygroscopic gases results from increased $\mathrm{pH}$ (caused by absorption of ammonia) and from the increased size of the fog/smog droplets. Our results indicate that unactivated fogs may become optically very thick when the droplet concentrations are on the order of several thousand per cubic centimeter of air.
\end{abstract}

\section{Introduction}

It has recently been shown that water-soluble gases that exist in high concentrations in polluted air, such as nitric acid $\left(\mathrm{HNO}_{3}\right)$, can increase the hygroscopicity of aerosol droplets as the gases dissolve into the aqueous phase (Kulmala et al., 1997; Laaksonen et al., 1998). Calculations have shown that at relative humidities slightly below $100 \%$ absorption of $\mathrm{HNO}_{3}$ may lead to appearance of micron sized droplet populations indistinguishable from ordinary clouds or fogs. This can occur even though the droplets have not undergone the traditional activation process, i.e. the droplets have not passed their Köhler curve maxima. Observations of unactivated fogs have been made in Po Valley, a rather polluted region in Italy (Frank et al., 1998).

Recent model calculations have shown that also $\mathrm{NH}_{3}$ has a substantial effect on cloud droplet formation (Kulmala et al., 1998; Hegg, 2000). The simultaneous dissolution of $\mathrm{NH}_{3}$ and $\mathrm{HNO}_{3}$ and/or $\mathrm{HCl}$ in the droplets can significantly in-

Correspondence to: H. Kokkola (harri.kokkola@uku.fi) crease the hygroscopicity of aerosol droplets and decrease the critical supersaturation at the droplet surface.

It should be noted that there exists a precondition for the unactivated cloud formation, regardless of the pollution levels: the droplets must follow their equilibrium (Köhler) curves very closely as they grow. With certain types of atmospheric clouds this would not be the case as the droplets are actually out of equilibrium because of kinetic limitations in water vapor condensation (Nenes et al., 2001). Considering gases such as $\mathrm{HNO}_{3}$, with mixing ratios orders of magnitude lower than those of water vapor, it is clear that the cooling has to be quite slow for the droplets to grow to micron size range retaining near-equilibrium all the time. Our preliminary cloud model calculations (Palonen, 2000) indicated that cooling rates on the order of $1 \mathrm{~K} /$ hour at $278.15 \mathrm{~K}$ and 1000 mbar are required for the unactivated cloud formation to occur due to the uptake of $\mathrm{HNO}_{3}$. Such cooling rates have been observed for radiation fogs (Roach et al., 1976).

The best known examples of radiation fogs formed at very polluted conditions were the infamous London smogs, which occurred during wintertime inversions. One of the features of these fogs was a very low visibility, at times only a few meters (Pearce, 1992). A low visibility hints at a high number concentration of relatively small droplets, and it is possible that at least a fraction of the London smogs were in fact unactivated fogs. Although it is clear that the low visibility was not caused by $\mathrm{HNO}_{3}$ in this case, it has been reported that large amounts of hydrochloric acid was released in the air for example during the occurrence of the 1952 "killer" smog (Met Office, 2002), and indeed, $\mathrm{HCl}$ could be a partial cause of the low visibility. Another possibility is that heterogeneous sulfate production in unactivated droplets was the source of additional hygroscopic material which made them grow to the micron size range without activation. Nowadays, sulfur dioxide pollution is generally much less than fifty years ago, but there are still locations for example in China and in some of the Eastern European countries where 
Table 1. The descriptions and properties of the models used in the calculations

\begin{tabular}{llll}
\hline model & thermodynamical module & gas-liquid mass transfer & sulfate chemistry \\
\hline Equilibrium model & AIM & Henry's law & yes \\
Cloud model I & AIM & diffusion & no \\
Cloud model II & EQUISOLV II & diffusion & yes \\
\hline
\end{tabular}

the mixing ratios of gaseous $\mathrm{SO}_{2}$ and concentrations of particulate sulfate in collected fog water can be quite high (Ye et al., 2003; Bridgman et al., 2002). These are also areas where intense fog episodes occur frequently during the wintertime (Stevens et al., 1995).

The purpose of this study is to investigate the effects of sulfate production in growing, unactivated droplet populations when $\mathrm{NH}_{3}$ and $\mathrm{HNO}_{3}$ are present in the gas phase. Our focus is in the development of the size distributions and droplet chemical compositions as a function of time, and in the reduction of visibility. Although the ammonia mixing ratios used in this study are comparable to those found for example in the Po Valley area (Fuzzi et al., 1992), and high nitrate concentrations have been found in fogwater in California (Jacob et al., 1985), we are not trying to specifically model any observed pollution fogs, but rather to take a step forward from the simple Köhler theory calculations, in order to qualitatively find out which kind of effects soluble trace gases may have on fog formation at heavily polluted conditions. Our future goal is to model observed pollution fogs; however, that will require more sophisticated models than those used in the present study. For example, when modeling the London type smogs, it would be highly desirable to describe the condensation of hydrochloric acid. However, the thermodynamic models best suited for our purposes do not account for $\mathrm{HCl}$. On the other hand, it has been shown that nitric and hydrochloric acids have very similar effects on cloud formation (Kulmala et al., 1996). Furthermore, in our model the sulfate is produced in chemical reactions between dissolved sulfur dioxide and ozone. It is likely that during wintertime fog formation the ozone levels are generally quite low, and probably the sulfate production in the London smogs was mostly due to oxidation of $\mathrm{SO}_{2}$ by $\mathrm{O}_{2}$, catalyzed by metals. However, the catalyzed oxidation mechanisms are still quite poorly understood, and difficult to model in a reliable manner. We therefore describe the sulfate production simply by using the $\mathrm{SO}_{2}-\mathrm{O}_{3}$-mechanism at artificially high ozone levels (when compared to usual wintertime inversion conditions). Despite of these divergences from the real conditions, we believe that our model results reveal features of radiation fog formation under high pollution that are qualitative correct regardless of the actual sulfate production mechanisms and acidic gases involved.

The models we are using in the present study are shown in Table 1. Most of our results are obtained with the Equilibrium model, in which the rate-limiting step is assumed to be the sulfate forming chemical reaction, and the uptake of all gases is determined by requiring that Henry's law equilibrium holds in the beginning of each time step. In the Cloud models I and II, gas-phase diffusion is explicitly accounted for all the species. Thus, we use Cloud model I, which has the same AIM thermodynamics (Clegg et al., 1998) as the Equilibrium model but no liquid phase chemistry, to assess the reliability of the Equilibrium model results at undersaturated conditions in the presence of nitric acid and ammonia. The Cloud model II has sulfate chemistry; however, the EQUISOLV II thermodynamics module (Jacobson, 1999b) tends to predict higher hydrogen ion concentrations than the AIM module, resulting in lower sulfate production. Although the EQUISOLV II predictions for sulfate production in activated cloud droplets are well comparable with those of other models (Kreidenweis et al., 2003), we find a rather large difference between AIM and EQUISOLV II at undersaturated conditions. We therefore do not compare the results from Cloud model II to the Equilibrium model results. Instead, we use Cloud model II for a sensitivity check, in which the properties of fogs formed at undersaturated and slightly supersaturated conditions are compared.

\section{Description of the models used in the calculations}

\subsection{Equilibrium model}

The equilibrium model to calculate the formation and the development of fog aerosol population is based on the inorganic aerosol thermodynamical equilibrium model AIM (Clegg et al., 1998). The AIM model determines activities, equilibrium gas partial pressures, and degrees of saturation with respect to solid phases in solutions containing water, and two or more of the ions $\left(\mathrm{H}^{+}, \mathrm{NH}_{4}^{+}, \mathrm{NO}_{3}^{-}\right.$and $\left.\mathrm{SO}_{4}^{2-}\right)$ or $\left(\mathrm{H}^{+}, \mathrm{NO}_{3}^{-}, \mathrm{SO}_{4}^{2-}, \mathrm{Cl}^{-}\right.$and $\left.\mathrm{Br}^{-}\right)$at temperatures from about $180 \mathrm{~K}$ to $330 \mathrm{~K}$. In our calculations there are $\mathrm{H}^{+}, \mathrm{NH}_{4}^{+}, \mathrm{NO}_{3}^{-}$ and $\mathrm{SO}_{4}^{2-}$ ions in the liquid phase. More details about AIM are presented in section 2.4 .

Using the AIM model the molalities of $\mathrm{NH}_{4}^{+}, \mathrm{NO}_{3}^{-}$in each size bin are solved from Eqs. (1) and (2)

$$
\begin{aligned}
& { }^{m} K_{\mathrm{HNO}_{3}}=\frac{\gamma_{\mathrm{NO}_{3}^{-}} m_{\mathrm{NO}_{3}^{-}} \gamma_{\mathrm{H}^{+}} m_{\mathrm{H}^{+}}}{p_{\mathrm{HNO}_{3}}} \\
& { }^{m} K_{\mathrm{NH}_{3}}=\frac{\gamma_{\mathrm{NH}_{4}^{+}} m_{\mathrm{NH}_{4}^{+}}}{\gamma_{\mathrm{H}^{+}} m_{\mathrm{H}^{+}} p_{\mathrm{NH}_{3}}}
\end{aligned}
$$


Table 2. Equilibrium coefficients (Seinfeld and Pandis, 1998)

\begin{tabular}{cll}
\hline Equilibrium & $\mathrm{A}\left(\mathrm{M}\right.$ or $\left.\mathrm{M} \mathrm{atm}^{-1}\right)$ & $\mathrm{B}(\mathrm{K})$ \\
\hline $\mathrm{SO}_{2}(\mathrm{~g}) \rightleftharpoons \mathrm{SO}_{2}(\mathrm{aq})$ & 1.2 & 10.48 \\
$\mathrm{SO}_{2}(\mathrm{aq}) \rightleftharpoons \mathrm{H}^{+}+\mathrm{HSO}_{3}^{-}$ & $1.3 \times 10^{-2}$ & 7.04 \\
$\mathrm{HSO}_{3}^{-} \rightleftharpoons \mathrm{H}^{+}+\mathrm{SO}_{3}^{2-}$ & $6.6 \times 10^{-8}$ & 3.74 \\
$\mathrm{O}_{3}(\mathrm{~g}) \rightleftharpoons \mathrm{O}_{3}(\mathrm{aq})$ & $1.3 \times 10^{-2}$ & 3.74 \\
\hline
\end{tabular}

the temperature dependence is defined as

$K_{e q}(\mathrm{~T})=A \exp \left[-B\left(\frac{1}{T}-\frac{1}{298 \mathrm{~K}}\right)\right]$

Table 3. Reaction coefficients (Seinfeld and Pandis, 1998)

\begin{tabular}{clll}
\hline Reaction & $\mathrm{A}\left(\mathrm{M}^{-1} \mathrm{~s}^{-1}\right)$ & $\mathrm{B}(\mathrm{K})$ & subscript \\
\hline $\mathrm{SO}_{2}(\mathrm{aq})+\mathrm{O}_{3}(\mathrm{aq})$ & $2.4 \times 10^{4}$ & & $a$ \\
$\mathrm{HSO}_{3}^{-}+\mathrm{O}_{3}(\mathrm{aq})$ & $3.7 \times 10^{5}$ & 5530 & $b$ \\
$\mathrm{SO}_{3}^{2-}+\mathrm{O}_{3}(\mathrm{aq})$ & $1.5 \times 10^{9}$ & 5280 & $c$
\end{tabular}

the temperature dependence is defined as

$k(\mathrm{~T})=A \exp \left[-B\left(\frac{1}{T}-\frac{1}{298 \mathrm{~K}}\right)\right]$

where ${ }^{m} K_{i}\left(\mathrm{~mol}^{2} \mathrm{~kg}^{-2} \mathrm{~atm}^{-1}\right)$ is the equilibrium constant, $m_{i}\left(\mathrm{~mol} \mathrm{~kg}^{-1}\right)$ is the molality and $\gamma_{i}$ is the molality based activity coefficient of solute species $i$, and $p_{\mathrm{HNO}_{3}}$ and $p_{\mathrm{NH}_{3}}\left(\mathrm{~atm}^{-1}\right)$ are the equilibrium partial pressures of nitric acid and ammonia at the surface of the droplet.

The charge balance requires that

$m_{\mathrm{H}^{+}}=m_{\mathrm{NO}_{3}^{-}}+2 m_{\mathrm{SO}_{4}^{2-}}+m_{\mathrm{HSO}_{4}^{-}}-m_{\mathrm{NH}_{4}^{+}}$

Sulfate is assumed to be completely non-volatile, so the amount of water in droplets $n_{\mathrm{H}_{2} \mathrm{O}}$ is calculated from equations

$S_{\mathrm{H}_{2} \mathrm{O}}=f_{\mathrm{H}_{2} \mathrm{O}}^{*} x_{\mathrm{H}_{2} \mathrm{O}} \exp \left(\frac{2 \sigma v_{\mathrm{H}_{2} \mathrm{O}}}{R T r_{p}}\right)$,

where $f_{\mathrm{H}_{2} \mathrm{O}}^{*}$ is the mole fraction based activity coefficient of water, $x_{\mathrm{H}_{2} \mathrm{O}}$ is the mole fraction of water, $\sigma$ is the surface tension of the droplet calculated according to Martin et al. (2000), $v_{\mathrm{H}_{2} \mathrm{O}}$ is the partial molar volume of water, $R$ is the gas constant, $T$ is the temperature and $r_{p}$ is the droplet radius.

Equations from 1 to 4 are solved among all the size bins. The system is assumed closed and the species in all size bins are assumed to be in equilibrium between the liquid and gas phase. Thus, the partial pressures of dissolved gas and water at the droplet surface for all the size bins are equal to the partial pressures in the gas phase.

\subsection{Oxidation of $\mathrm{S}(\mathrm{IV})$ to $\mathrm{S}(\mathrm{VI})$}

In the model, the gaseous phase includes $\mathrm{NH}_{3}, \mathrm{HNO}_{3}, \mathrm{SO}_{2}$ and $\mathrm{O}_{3}$. The gaseous $\mathrm{SO}_{2}$ dissolves into the liquid phase according to the following dissociation reactions:

$$
\begin{aligned}
\mathrm{SO}_{2}(\mathrm{~g}) & \rightleftharpoons \mathrm{SO}_{2}(\mathrm{aq}) \\
\mathrm{SO}_{2}(\mathrm{aq}) & \rightleftharpoons \mathrm{H}^{+}+\mathrm{HSO}_{3}^{-} \\
\mathrm{HSO}_{3}^{-} & \rightleftharpoons \mathrm{H}^{+}+\mathrm{SO}_{3}^{2-}
\end{aligned}
$$

The equilibrium constants and their temperature dependencies are shown in Table 2.

Dissolved ozone reacts with liquid S(IV) producing sulfuric acid. To calculate the reaction rate we used the rate expression where all forms of dissolved S(IV) react with ozone (Seinfeld and Pandis, 1998)

$\frac{d[\mathrm{~S}(\mathrm{IV})]}{d t}=\left\{k_{a}\left[\mathrm{SO}_{2}(\mathrm{aq})\right]+k_{b}\left[\mathrm{HSO}_{3}^{-}\right]+k_{c}\left[\mathrm{SO}_{3}^{2-}\right]\right\}\left[\mathrm{O}_{3}\right](8)$

The reaction coefficients and their temperature dependencies are shown in Table 3.

The liquid phase diffusion and the gas phase diffusion are assumed to be fast so the rate determining sub-process in the oxidation is assumed to be the chemical reaction. Accordingly, the concentrations of dissolved gases are uniform inside the droplets.

Ozone oxidizes sulfur dioxide slowly compared to for example hydrogen peroxide $\mathrm{H}_{2} \mathrm{O}_{2}$, so using it as an oxidant gives a lower amount of sulfate production in droplets but shows qualitatively the effect of sulfate production on droplet growth and visibility.

\subsection{Cloud microphysics model}

The equilibrium model is only valid when the relative humidity is less than $100 \%$ and the droplets are unactivated. When the droplets reach the critical diameter for activation they grow spontaneously and the system can not reach equilibrium. In the simulations in which droplet activation occurs, we used a cloud microphysics model (Kokkola et al., 2003). The cloud microphysics model calculates condensational non-equilibrium growth of an aerosol population. It includes explicit microphysics of cloud droplet growth for a rising or a static air parcel. The condensation equations used in the cloud microphysics are based on equations given by Kulmala (1993).

\subsection{Thermodynamical models}

The thermodynamical model used in the cloud microphysics model can be either AIM or EQUISOLV II. The AIM model uses Pitzer, Simonson and Clegg method for calculating mole fraction based activity coefficients for single ions (Clegg et al., 1998). The EQUISOLV II uses Pitzer method and parameterizations on measurement and model data for obtaining binary activity coefficients and Bromley mixing rule (Bromley, 1973; Jacobson, 1999a) for mixed activity coefficients. The thermodynamical equilibrium is calculated in 


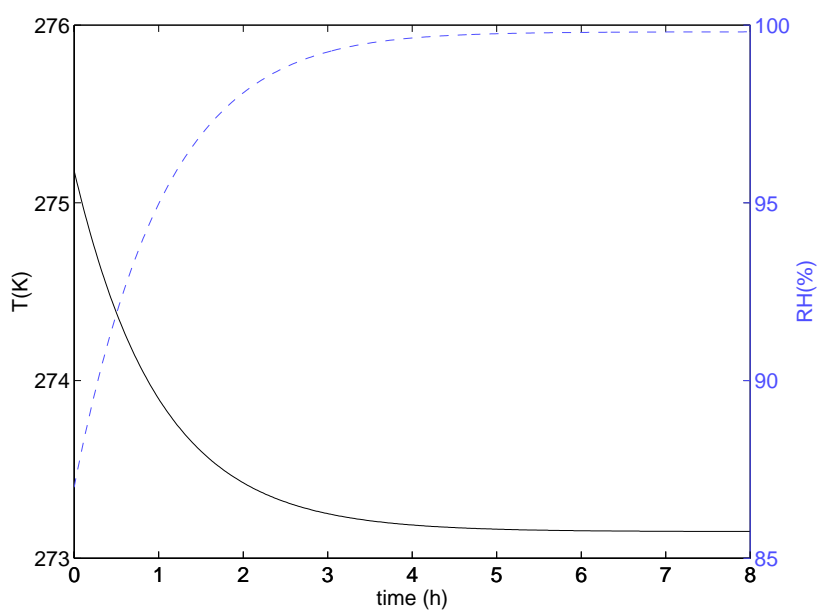

Fig. 1. Relative humidity (dash line) and temperature (solid line) as a function of time for an 8 hour run.

AIM by minimization of Gibbs free energy of the system using sequential quadratic programming algorithm. In EQUISOLV II, the thermodynamical equilibrium is obtained using analytical equilibrium iteration and mass flux iteration (Jacobson, 1999a,b).

\subsection{Visibility}

All the models also include a common module for calculating the effect of the droplet population on the visibility. The visual range $x_{v}$ was evaluated as the distance at which a black object has a standard 0.02 contrast ratio against a white background (Seinfeld and Pandis, 1998). The visual range for a given particle population was calculated from

$x_{v}=\frac{3.912}{b_{\text {ext }}(\lambda)}$,

where $b_{\text {ext }}$ is the extinction coefficient for light with wavelenght $\lambda$ (Seinfeld and Pandis, 1998).

The extinction coefficient was calculated from

$b_{\text {ext }}(\lambda)=\int_{0}^{D_{p}^{\max }} \frac{\pi D_{p}^{2}}{4} Q_{\text {ext }}\left(m, \lambda, D_{p}\right) n\left(D_{p}\right) d D_{p}$

where $Q_{\text {ext }}$ is the extinction efficiency and $m$ is the refractive index of the particles. The calculation of extinction coefficient is presented in detail by Bohren and Huffman (1983). The refractive index for the particle was assumed constant at $m=1.5-0.03 i$ for all the size bins.

\section{Model calculations}

We made calculations for typical meteorological conditions of wintertime smog episodes. The smog episodes usually occur when there is a temperature inversion and low wind speed. The temperature inversion prevents vertical convection of gases and the low horizontal flow is not sufficient enough to remove the air pollution, so the air pollution is trapped in the atmosphere's lowest layer. In the calculations the system for the trace gases is assumed closed.

We made Equilibrium model runs for five different combinations of gas phase pollutants to compare how different mechanisms affect the size distribution. In all the runs we applied a log-normally distributed ammonium sulfate [ $\left.\left(\mathrm{NH}_{4}\right)_{2} \mathrm{SO}_{4}\right]$ particle population which was divided to 39 size bins. The geometrical mean diameter $D_{p}$ of the particles was $200 \mathrm{~nm}$ and the geometrical standard deviation $\sigma_{p g}$ of the population was 1.5. The total number concentration of the particles was $1000 \mathrm{~cm}^{-3}$. We also repeated one of the runs using a particle concentration of $10000 \mathrm{~cm}^{-3}$.

In the simulations, the temperature was decreased from $3^{\circ} \mathrm{C}$ to $0{ }^{\circ} \mathrm{C}$ as shown in Fig. 1 . As the temperature decreases, the relative humidity increases from $87 \%$ to $99.98 \%$ (Fig. 1).

The initial gas phase volume mixing ratios in the simulations for the trace gases were: $\left[\mathrm{SO}_{2}\right]=400 \mathrm{ppb},\left[\mathrm{O}_{3}\right]=$ $10 \mathrm{ppb},\left[\mathrm{HNO}_{3}\right]=5 \mathrm{ppb}$ and $\left[\mathrm{NH}_{3}\right]=10 \mathrm{ppb}$. However, since the first step of the model run is to equilibrate the gases with the liquid phase, most of the nitric acid and roughly half of the ammonia were partitioned into the droplets already in the beginning of each simulation (the remaining gas phase volume mixing ratio of $\mathrm{HNO}_{3}$ is approximately $50 \mathrm{ppt}$ ).

The first Equilibrium model run was executed without gasphase pollutants so the growth of particles was basically according to the Köhler theory only with the difference that negligible amount of $\mathrm{NH}_{3}$ originating from ammonium sulfate exits the droplets into the gas-phase. In the second run, $\mathrm{SO}_{2}$ and $\mathrm{O}_{3}$ were introduced into the gas phase, so this simulation shows the effect of sulfate production when there are no hygroscopic gases. In the third run, there was $\mathrm{HNO}_{3}$ and $\mathrm{NH}_{3}$ in the gas phase. Dissolution of the pollutants increases the hygroscopicity of the droplets and enhances their growth. In the fourth run, $\mathrm{SO}_{2}, \mathrm{O}_{3}, \mathrm{HNO}_{3}$ and $\mathrm{NH}_{3}$ were present in the gas-phase, creating a combined effect of increased hygroscopicity and sulfate production to enhance the growth of droplets. The fifth run was otherwise similar as the fourth one, but there was no $\mathrm{HNO}_{3}$ in the system. The effect of increased particle concentration was studied by repeating the fourth model run with 10000 particles per $\mathrm{cm}^{3}$.

\section{Results and discussion}

\subsection{Equilibrium model simulations}

Figure 2 shows the final $(t=8 \mathrm{~h})$ size distributions from a variety of Equilibrium model runs. It can be seen that with no nitric acid and ammonia in the system, the presence of sulfate producing precursors $\mathrm{SO}_{2}$ and $\mathrm{O}_{3}$ slightly increase the size of droplets, especially the larger ones, also making the size distribution wider (blue solid line). The initial size distribution is almost exactly equal to the case of clean air, 


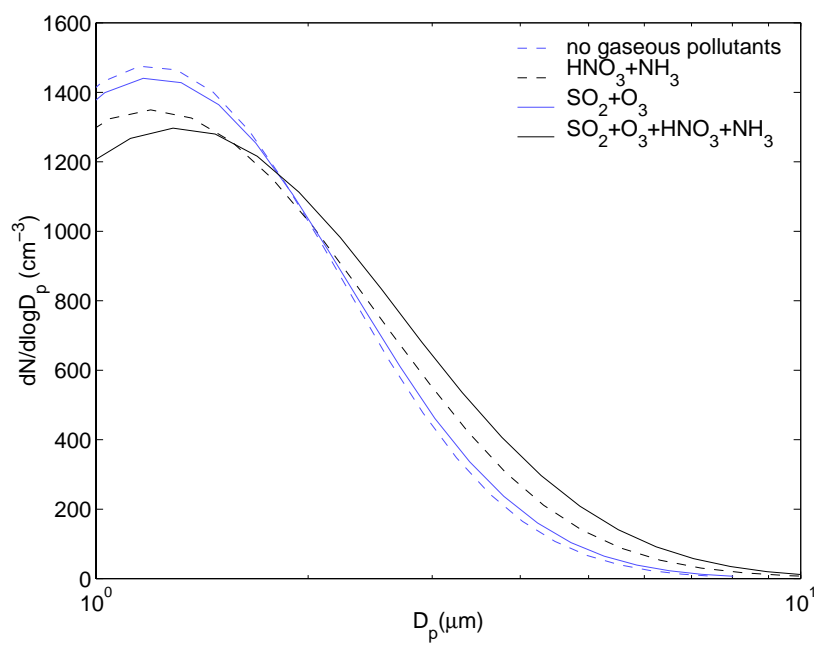

Fig. 2. Number size distribution at the end of the simulation for four different cases: with no gaseous pollutants (blue dashed line), with $\mathrm{SO}_{2}$ and $\mathrm{O}_{3}$ only (blue solid line), with $\mathrm{HNO}_{3}$ and $\mathrm{NH}_{3}$ only (black dashed line), and with $\mathrm{SO}_{2}, \mathrm{O}_{3}, \mathrm{HNO}_{3}$, and $\mathrm{NH}_{3}$

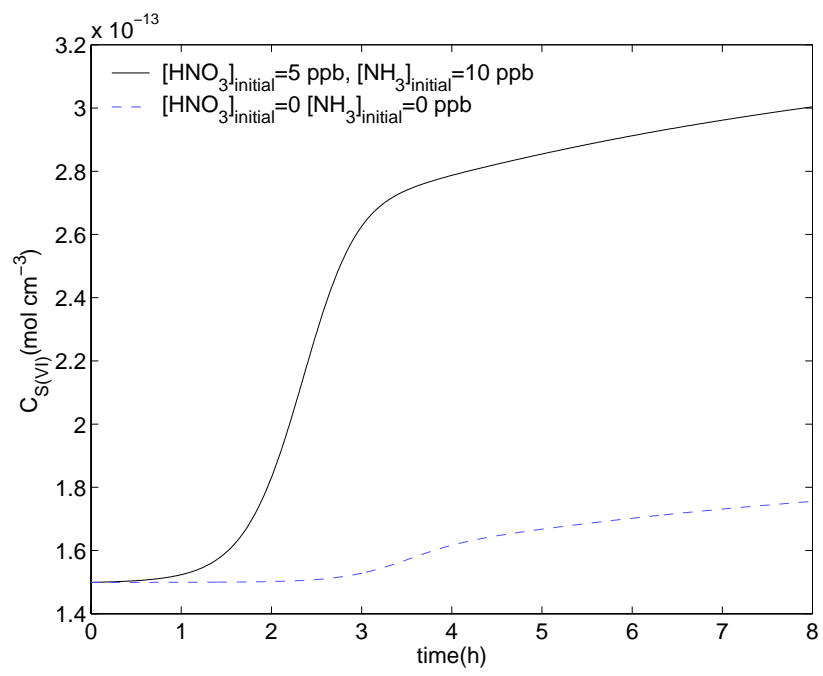

Fig. 3. Sulfate concentration as a function of time.

because dissolved $\mathrm{SO}_{2}$ and $\mathrm{O}_{3}$ have very little effect on the size of the droplets at $87 \% \mathrm{RH}$.

Figure 2 furthermore shows that the hygroscopic gases $\mathrm{HNO}_{3}$ and $\mathrm{NH}_{3}$ have a significant effect on the size of the droplets (black dashed line). For example, in this run, the largest size bin grows 1.5 times larger than in the case with no gaseous pollutants. $\mathrm{HNO}_{3}$ and $\mathrm{NH}_{3}$ affect the size distribution already in the beginning of the run. When $\mathrm{HNO}_{3}$ and $\mathrm{NH}_{3}$ coexist in the gas phase, their solubilities are increased, allowing them to dissolve in the liquid phase already at fairly low relative humidities.

The sulfate production further increases the size of the droplets and also makes the size distribution wider (black solid line in Fig. 2). In this run, the largest size bin grows

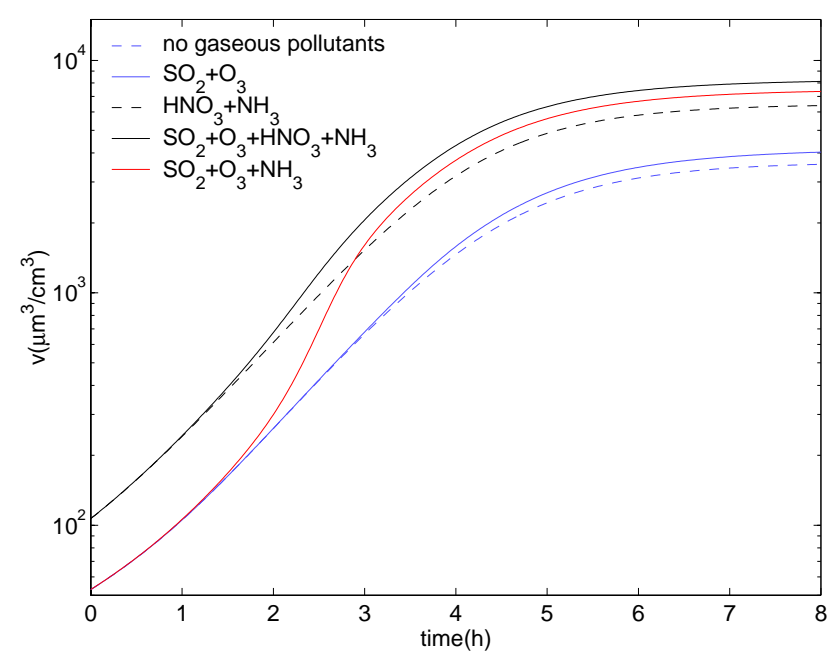

Fig. 4. Total volume concentration of all size bins as a function of time for four different runs

2.2 times larger than in the case of clean air. The initial size distribution in this case equals almost exactly the size distribution with the case with only hygroscopic gases but no sulfate production.

Figure 3 shows the amount of sulfate produced in the cases without hygroscopic gases (dashed line) and with hygroscopic gases (solid line). The absorption of $\mathrm{HNO}_{3}$ and $\mathrm{NH}_{3}$ makes the droplets more hygroscopic, resulting in increased water vapor uptake and droplet volumes, which in turn facilitates increased sulfate production. The effect of gaseous pollutants on the total volume of the droplets can be seen in Fig. 4. $\mathrm{HNO}_{3}$ and $\mathrm{NH}_{3}$ cause the volume of the droplets to grow significantly. Sulfate production also enhances the hygroscopicity of the droplets, causing further growth of the droplets both in the presence of $\mathrm{HNO}_{3}+\mathrm{NH}_{3}$ and in the presence of $\mathrm{NH}_{3}$ alone. Ammonia is not very water soluble, and therefore, if nitric acid is excluded from the system, it is absorbed by the droplets only when enough of sulfate has been produced, in this case after about 1.5 hours from the beginning of the run.

We also made a simulation with $15 \mathrm{ppb}$ of $\mathrm{HNO}_{3}$ and zero ammonia in the system. In this case, the droplet population grew as efficiently during the first 3 hours as in the presence of nitric acid and ammonia; however, sulfate production was negligible due to low $\mathrm{pH}$ of the droplets. After 3 hours the largest size class started growing very fast whereas the rest of the population stayed almost constant. This behavior will be explained in the article by Kokkola et al. (2003b).

Figure 5 shows the gas phase concentrations as a function of time when all pollutants are present in the system. In the beginning of the run the gas phase concentration of $\mathrm{HNO}_{3}$ decreases as it partitions into the liquid phase. However, at about $4 \mathrm{~h}$ from the start the concentration starts to increase again due to the fact that the $\mathrm{pH}$ in the droplets decreases 


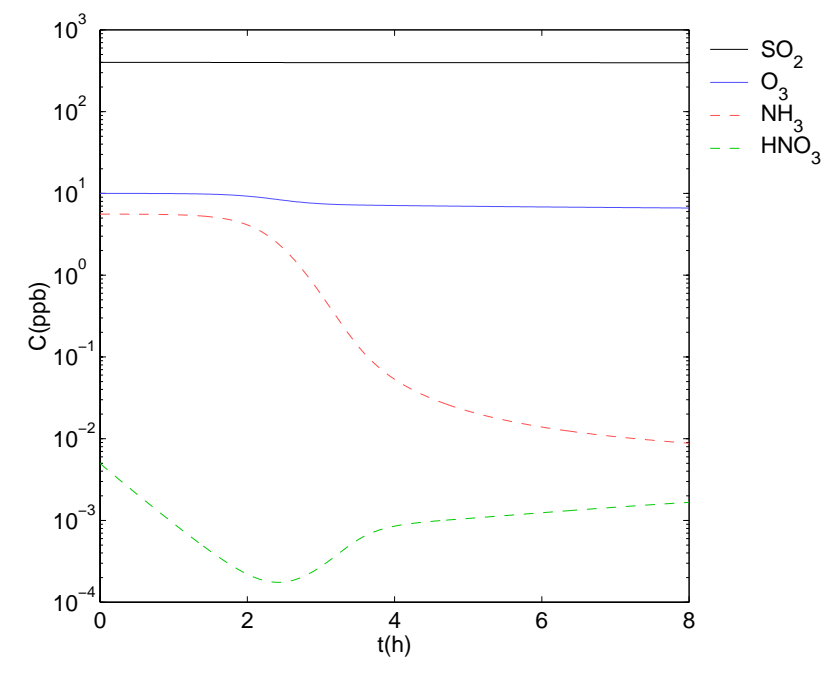

Fig. 5. Gas phase concentrations as a function time.

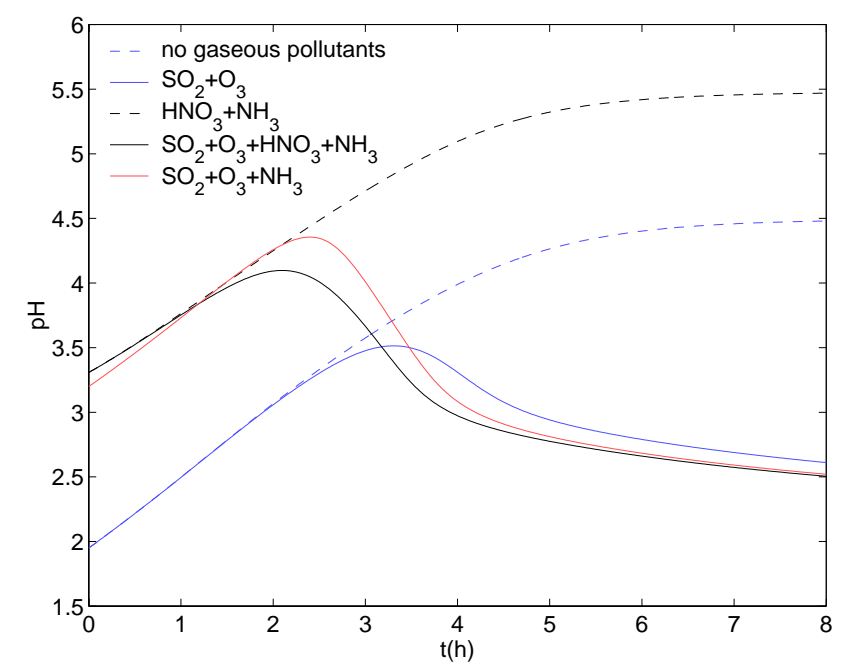

Fig. 6. $\mathrm{pH}$ of the largest size bin as a function of time.

because of the sulfate production, driving nitric acid out of the droplets. Figure 6 shows the $\mathrm{pH}$ in the largest droplets as a function of time in the five cases considered. Sulfate production causes the final $\mathrm{pH}$ to approach 2.5. It has been estimated that in the London fogs, the $\mathrm{pH}$ was as low as 2 or even below.

To study the effect of enhanced sulfate production on the size distribution of the droplets, we made runs at very high ozone levels, and runs in which an increased reaction coefficient was applied. How these changes affect the total volume concentration can be seen in Fig. 7. In the beginning of the runs, the extra sulfate production increases the volume of the droplets. But as the $\mathrm{pH}$ of the droplets decreases as shown in Fig. 7, the production of sulfate decreases. Thus, at around 3,5 hours from the beginning of the runs, the amount of hygroscopic matter, and thereby the sizes of the droplets, are

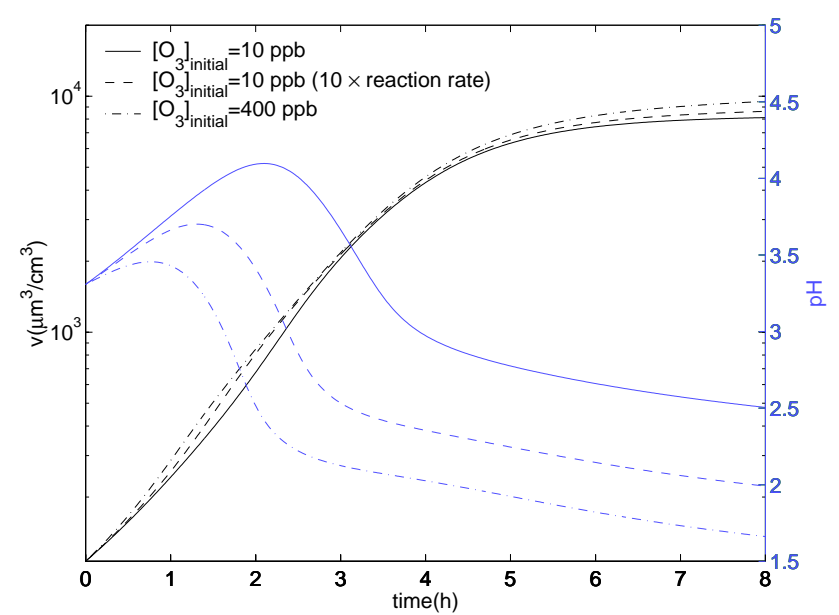

Fig. 7. Total volume concentration of all size bins and the $\mathrm{pH}$ of the largest size bin as a function of time for three different runs. Nitric acid and ammonia are present in the system.

roughly the same. Towards the end the $\mathrm{pH}$ of the droplets decreases in all the runs, and in the systems with higher sulfate production the droplets grow larger.

The number of particles in polluted conditions can be very high, so to investigate the effect of increased particle number concentration, we repeated the simulation with $\mathrm{HNO}_{3}, \mathrm{NH}_{3}$, $\mathrm{SO}_{2}$ and $\mathrm{O}_{3}$ using a particle concentration of $10^{4} \mathrm{~cm}^{-3}$. As shown in Fig. 8, the effect of trace gases on the final size distribution is qualitatively similar regardless of the absolute droplet concentration. Nevertheless, as the number concentration of particles is high, the effect of hygroscopic gases is diminished because there is less nitric acid and ammonia per droplet. The mean diameter is therefore significantly smaller for the droplet population with higher number concentration. Furthermore, the tenfold increase in droplet concentration results in a roughly twofold increase in the final total volume of droplets, and in the amount of sulfate produced.

The visual range was calculated at $\lambda=523 \mathrm{~nm}$ wavelength. The effect of $\mathrm{HNO}_{3}$ and $\mathrm{NH}_{3}$ can been seen already in the beginning of the run. For the two runs where there is no $\mathrm{HNO}_{3}$ or $\mathrm{NH}_{3}$ in the gas phase the visual range at the start of the run is $10038 \mathrm{~m}$. This number drops to $5882 \mathrm{~m}$ when $\mathrm{HNO}_{3}$ and $\mathrm{NH}_{3}$ are present in the system.

After $8 \mathrm{~h}$ the visual range has decreased to $790 \mathrm{~m}$ in the clean air case. $\mathrm{SO}_{2}$ and $\mathrm{O}_{3}$ reduce the visual range to $748 \mathrm{~m}$, and $\mathrm{HNO}_{3}$ and $\mathrm{NH}_{3}$ to $618 \mathrm{~m}$. With all the trace gases $\mathrm{SO}_{2}$, $\mathrm{O}_{3}, \mathrm{HNO}_{3}$ and $\mathrm{NH}_{3}$ present in the system, the visibility is reduced to $521 \mathrm{~m}$.

\subsection{Comparison of Equilibrium and Cloud models}

The Cloud model simulations were made using the same size distribution, temperature profile, and gas phase concentrations as were used with the Equilibrium model. 


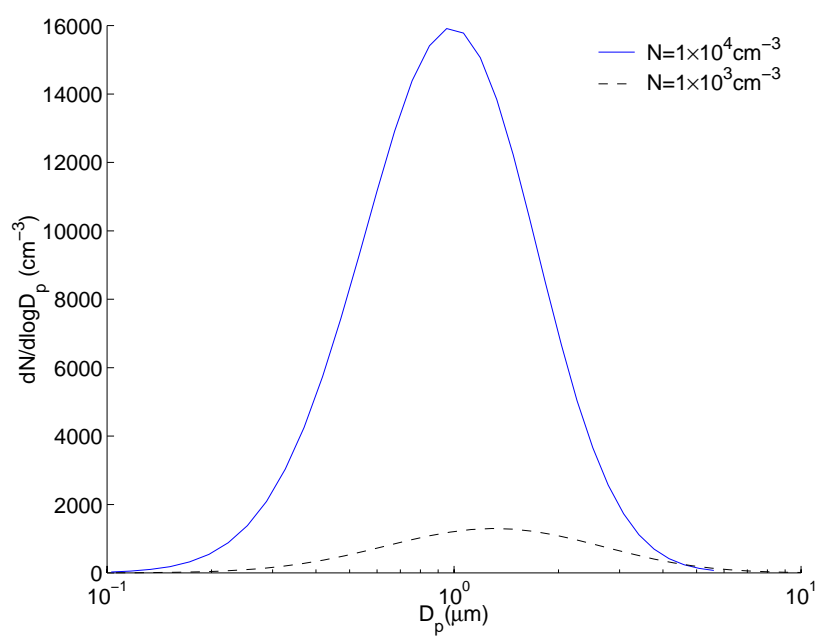

Fig. 8. Final distribution for particle population for which the total number concentration is $10^{3} \mathrm{~cm}^{-3}$ (dashed line) $10^{4} \mathrm{~cm}^{-3}$ (solid line).

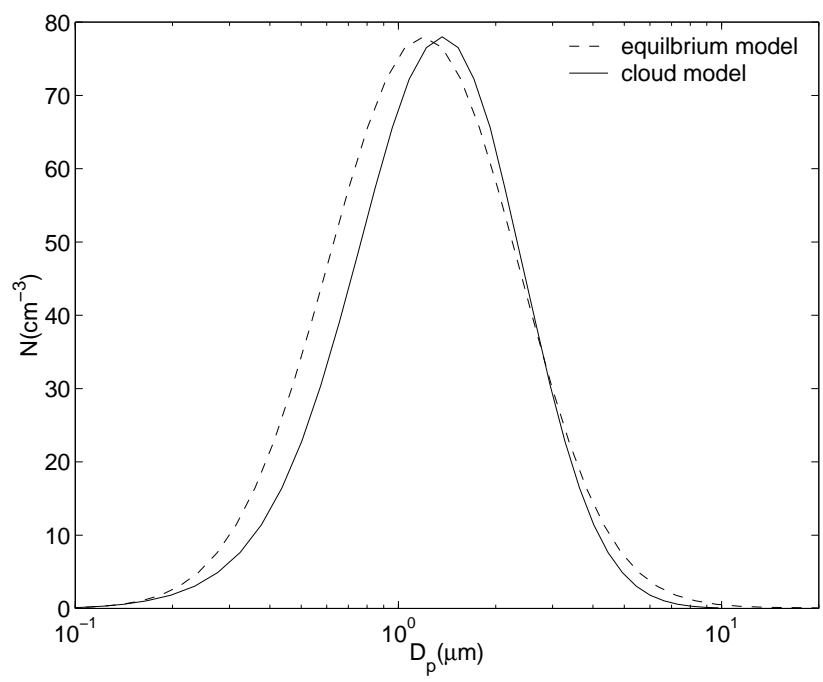

Fig. 9. Equilibrium model vs cloud microphysics model.

Figure 9 shows the calculated number size distribution at the end of the run for both Equilibrium model (dashed line) and the Cloud model (solid line) for the simulation with $5 \mathrm{ppb}$ of nitric acid and $10 \mathrm{ppb}$ of ammonia. The resulting size distributions match each other quite closely, especially for the largest droplets, which have the most significant effect on the visibility of the fog. The sizes of the smallest droplets are somewhat underestimated when using the Equilibrium model. However, the two distributions are similar enough for us to conclude that the results obtained using the Equilibrium model are qualitatively correct.

The calculated visibility at the end of the simulation, with nitric acid and ammonia in the system given by the Cloud model is $616 \mathrm{~m}$ and corresponds well to the $618 \mathrm{~m}$ visibility given by the Equilibrium model.

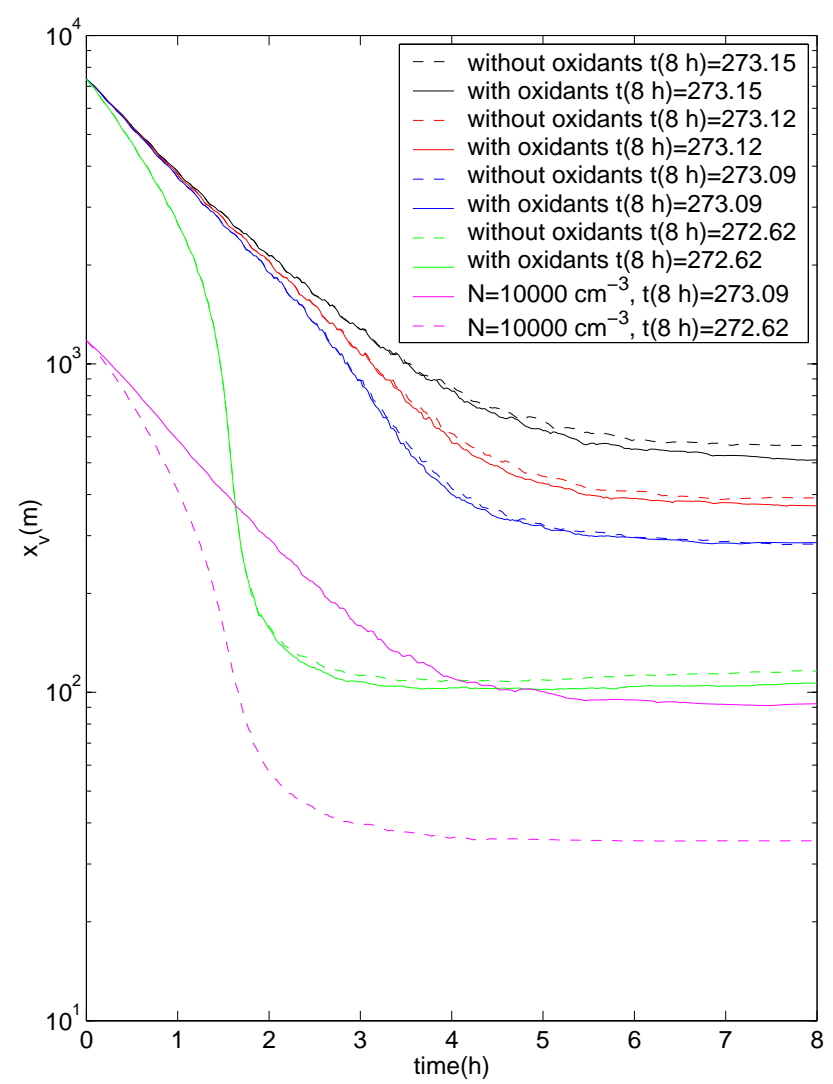

Fig. 10. Visual range $x_{v}$ as a function of time for ten different cases.

\section{The effect of final temperature on the results}

Since the equilibrium size of the droplets near $100 \%$ relative humidity is extremely sensitive to the final temperature, we made simulations in which the final temperature was decreased by up to $0.5 \mathrm{~K}$. Since this is enough for reaching supersaturated conditions, the calculations were made using the Cloud model II. The simulations were made for a system with initial volume mixing ratios of $5 \mathrm{ppb}$ and $10 \mathrm{ppb}$ for nitric acid and ammonia, respectively, and both with and without $\mathrm{SO}_{2}$ and $\mathrm{O}_{3}$. For the cases with $\mathrm{SO}_{2}$ and $\mathrm{O}_{3}$ their initial volume mixing ratios were $400 \mathrm{ppb}$ and $10 \mathrm{ppb}$, respectively.

Figure 10 shows the calculated visibility for these simulations. The black, red, and blue lines represent simulations with 1000 droplets per $\mathrm{cm}^{3}$ at undersaturated conditions. As can be seen, the visibility is very sensitive to the final temperature. A dramatic change can be seen when the final temperature is decreased to $272.62 \mathrm{~K}$, resulting in supersaturated conditions and activation of droplets (green lines). At around 2 hours into the simulation, the visibility has dropped close to $100 \mathrm{~m}$, whereas the visibility for the three unactivated fogs is still around $2 \mathrm{~km}$. However, the difference decreases considerably toward the end of the simulations.

The magenta lines in Fig. 10 show the visibility in two simulations with a droplet concentration of $10^{4} \mathrm{~cm}^{-3}$. When the 


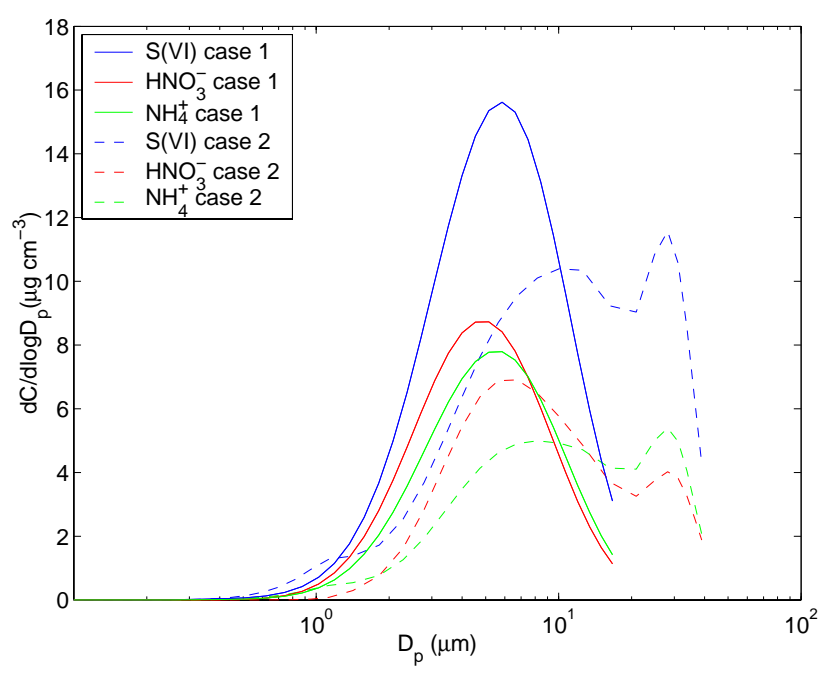

Fig. 11. Calculated ion size distribution for sulfate (blue lines), nitrate (red lines) and ammonium ions (green line), for unactivated case (solid lines) and activated case (dashed lines).

final temperature is $273.09 \mathrm{~K}$, the visibility drops from 300 to $90 \mathrm{~m}$ compared to the case with 1000 droplets per $\mathrm{cm}^{3}$. When the final temperature is decreased to $276.62 \mathrm{~K}$, the resulting visibility is only around 35 meters. Very notably, this fog (the dashed magenta line in Fig. 10) is not activated. Because of the high number concentration, the condensation is so intense that the saturation ratio stays below unity throughout the simulation. As Frank et al. (1998) have shown, high mass load of particles can play significant part in the formation of unactivated fogs. With droplet concentrations of several thousand per $\mathrm{cm}^{3}$, the cooling rate has to be quite high for the droplets to be activated.

Finally, Fig. 11 shows the concentration of ions in different sized droplets for an unactivated droplet population (case 1, solid lines) and an activated droplet population (case 2, dashed lines). The case 1 corresponds to the simulation with all the trace gases present in the system and a final temperature of $273.15 \mathrm{~K}$. Case 2 is otherwise similar to case 1 except that the final temperature is $272.62 \mathrm{~K}$. The bimodal ion size distributions for the activated case are quite comparable to those given by Hoag et al. (1999). The unactivated distributions, on the other hand, are very different, showing unimodal behavior and mode sizes differing only slightly for the various ions. The difference between the activated and unactivated ion size distributions could possibly be exploited in experimental identification of unactivated fogs.

\section{Conclusions}

We have studied the effects of soluble gases and sulfate production on the formation and properties of radiation fogs. The effect of sulfate production alone on the droplet size distribution was rather modest; however, we applied the S(IV) oxidation mechanism by dissolved ozone, which is relatively inefficient especially at low $\mathrm{pH}$ values. Dissolved $\mathrm{HNO}_{3}$ and $\mathrm{NH}_{3}$ had a stronger effect on the size distribution, making it wider. This can be understood by noting that, due to a weaker Kelvin effect, larger droplets absorb soluble gases more effectively than do smaller ones.

Very significantly, our simulations showed that ammonia and nitric acid effectively boost sulfate formation in the droplets. Ammonia affects sulfate formation by keeping the droplet $\mathrm{pH}$ at a higher level than would otherwise be the case, whereas the additional effect of $\mathrm{HNO}_{3}$ is caused by its hygroscopicity - the droplets take up more water due to absorption of nitric acid, and thus the total volume facilitating sulfate formation becomes larger.

The reduction of visibility by unactivated fogs was seen to become very efficient with increasing droplet concentrations. With $10^{4}$ droplets per $\mathrm{cm}^{3}$, the visibility dropped almost to a tenth of that calculated for 1000 droplets per $\mathrm{cm}^{3}$, despite of the fact that the higher droplet concentration resulted only in a doubled total volume of the droplets. Further reduction in visibility may result from light absorbing components (soot), more effective sulfate oxidation mechanisms, and continuous release of hygroscopic gases into the air during the fog formation. In the future, our goal is to simulate observed pollution fogs using a cloud model which incorporates these aspects.

Acknowledgements. This work was supported by the Academy of Finland.

\section{References}

Bohren, C.F. and Huffman, D. R.: Absorption and scattering of light by small particles, John Wiley \& Sons inc., 1983.

Bridgman, H. A., Davies, T. D., Jickells, T., Hunova, I., Tovey, K., Bridges, K., and Surapipith, V.: Air pollution in the Krusne Hory region, Czech Republic during the 1990s, Atmos. Environ., 36, 3375-3389, 2002.

Bromley, A. L.: Thermodynamical properties of strong electrolytes in aqueous solutions, AIChE J., 19, 313-320, 1973.

Clegg, S. L., Brimblecombe, P., and Wexler, A. S.: Thermodynamical model of the system $\mathrm{H}^{+}-\mathrm{NH}_{4}^{+}-\mathrm{SO}_{4}^{2-}-\mathrm{NO}_{3}^{-}-\mathrm{H}_{2} \mathrm{O}$ at tropospheric temperatures, J. Phys. Chem. A, 102, 2137-2154, 1998.

Frank, G., Martinsson, B. G., Cederfelt, S., Berg, O. H., Swietlick, E., Wendisch, M., Yuskiewicz, B., Heitzenberg, J., Wiedensohler, A., Orsini, D., Stratmann, F., Laj, P., and Ricci, L.: Droplet formation and growth in polluted fogs, Contr. Atmos. Phys., 71, 65-85, 1998.

Fuzzi, S., Facchini, M.C., Lind, J. A., Wobrock, W., Kessel, M., Maser, R., Jaeschke, W., Enderle, K. H., Arends, B. G., Berner, A., Solly, I., Kruisz, C., Reischl, G., Pahl, S., Kaminski, U., Winkler, P., Ogren, J. A., Noone, K. J., Hallberg, A., FierlingerOberlinninger, H., Puxbaum, H., Marzorati, A., Hansson, H.-C., Wiedensohler, A., Benningson, I. B., Martinsson, B. G., Schell, D., and Georgii, H. W.: The Po Valley fog experiment 1989, An overview, Tellus, 44B, 448-468, 1992. 
Hegg, D. A.: Impact of gas-phase $\mathrm{HNO}_{3}$ and $\mathrm{NH}_{3}$ on microphysical processes in atmospheric clouds, Geophys. Res. Lett., 27, 22012204, 2000.

Hoag, K. J., Collett, J. L., Jr., and Pandis, S. N.: The influence of drop size-dependent fog chemistry on aerosol processing by San Joaquin Valley fogs, Atmos. Environ., 33, 4817-4832, 1999.

Jacob, D. J., Waldman, J. M., and Hoffman, M. R.: Chemical composition of fogwater collected along the California coast, Environ. Sci. Technol., 19, 730-736, 1985.

Jacobson, M.Z.: Fundamentals of Atmospheric Modeling, Cambridge University Press, 1999a.

Jacobson, M.Z.: Studying the effects of calcium and magnesium on size-distributed nitrate and ammonium with EQUISOLV II, Atmos. Environ., 33, 3635-3649, 1999b.

Kokkola, H., Romakkaniemi, S., and Laaksonen, A.: A onedimensional cloud model including trace gas condensation and sulfate chemistry, (submitted to Boreal Env. Res.), 2003a.

Kokkola, H., Romakkaniemi, S., and Laaksonen, A.: Köhler theory for a polydisperse droplet population in the presence of a soluble trace gas, and an application to stratospheric sts droplet growth, (submitted to Atmos. Chem. Phys. Discuss.), 2003b.

Kreidenweis, S. M., Walcek, C. J., Feingold, G., Gong, W., Jacobson, M.Z., Kim, C.-H., Liu, X., Penner, J.E., Nenes, A., and Seinfeld, J.H.: Modification of aerosol mass and size distribution due to aqueous-phase $\mathrm{SO}_{2}$ oxidation in clouds: Comparison of several models, J. Geophys. Res., 108, 2003.

Kulmala, M.: Condensational growth and evaporation in the transitional regime, Aerosol Sci. Tech., 19, 381-388, 1993.

Kulmala, M., Laaksonen, A., Aalto, P., Vesala, T., and Pirjola, L.: Formation, growth, and properties of atmospheric aerosol particles and cloud droplets, Geophysica, 32, 217-233, 1996.

Kulmala, M., Laaksonen, A., Charlson, R. J., and Korhonen, P.: Clouds without supersaturation, Nature, 388, 336-337, 1997.
Kulmala, M., Toivonen, A., Mattila, T., and Korhonen, P.: Variations of cloud droplet concentrations and the optical properties of clouds due to changing hygroscopicity: A model study, J. Geophys. Res., 103, 16 183-16 195, 1998.

Laaksonen, A., Korhonen, P., Kulmala, M., and Charlson, R. J.: Modification of the Köhler equation to include soluble trace gases and slightly soluble substances., J. Atmos. Sci., 55, 853862, 1998.

Martin, E., George, C., and Mirabel, P.: Densities and surface tensions of $\mathrm{H}_{2} \mathrm{SO}_{4} / \mathrm{HNO}_{3} / \mathrm{H}_{2} \mathrm{O}$ solutions., Geophys. Res. Lett., 27, 197-200, 2000.

Met Office: The great smog of 1952, http://www.met-office.gov.uk/ education/historic/smog.html, 2002.

Nenes, A., Ghan, S., Abdul-Razzak, H., Chuang, P., and Seinfeld, J.: Kinetic limitations on cloud droplet formation and impact on cloud albedo, Tellus, 53B, 133-149, 2001.

Palonen, V.: Formation mechanism of smog, Master's thesis, University of Kuopio, Finland, (in Finnish), 2000.

Pearce, F.: Back to the days of deadly smogs, New Scientist, pp. 25-28, 1992.

Roach, W. T., Brown, R., Caughey, S. J., Garland, J. A., and Readings, C. J.: The physics of radiation fog: I - a field study., Quart J. R. Met. Soc., 102, 313-333, 1976.

Seinfeld, J.H. and Pandis, S. N.: Atmospheric Chemistry and Physics, John Wiley \& Sons inc., 1998.

Stevens, R. K., Pinto, J., Shoaf, C. R., Hartlage, T. A., Metcalfe, J., Preuss, P., Willis, R. D., and Mamane, Y.: Czech air quality monitoring and receptor modeling study, J. Aer. Sci., 26, 1022, 1995.

Ye, B., Ji, X., Yang, H., Yao, X., Chan, C. K., Cadle, S. H., Chan, T., and Mulawa, P. A.: Concentration and chemical composition of PM2.5 in Shanghai for a 1-year period, Atmos. Environ., 37, 499-510, 2003. 